\title{
The log odds of positive neck lymph nodes is a superior lymph node predictor for overall survival in head and neck cancer: a population-based analysis in Germany
}

\author{
Mussab Kouka ${ }^{1}$ - Elisa Al-Ahmar ${ }^{1}$. Jens Büntzel ${ }^{2} \cdot$ Holger Kaftan $^{3} \cdot$ Daniel Böger $^{4} \cdot$ Andreas Müller $^{5}$. \\ Stefan Schultze-Mosgau ${ }^{6} \cdot$ Thomas Ernst $^{7} \cdot$ Orlando Guntinas-Lichius $^{1}{ }^{10}$
}

Received: 14 September 2021 / Accepted: 3 November 2021 / Published online: 22 November 2021

(c) The Author(s) 2021

\begin{abstract}
Background This population-based study investigated the influence of different lymph node (LN) classifications on overall survival (OS) in head and neck cancer (HNC).

Methods 401 patients (median age: 57 years; $47 \%$ stage IV) of the Thuringian cancer registries with diagnosis of a primary HNC receiving a neck dissection (ND) in 2009 and 2010 were included. OS was assessed in relation to total number of LN removed, number of positive LN, LN ratio, and log odds of positive LN (LODDS).

Results Mean number of LODDS was $0-0.96 \pm 0.57$. When limiting the multivariate analysis to TNM stage, only the UICC staging (stage IV: HR 9.218; 95\% CI 2.721-31.224; $p<0.001$ ) and LODDS > 1.0 (HR 2.120; 95\% CI 1.129-3.982; $p=0.019$ ) were independently associated with lower OS.

Conclusion LODDS was an independent and superior predictor for OS in HNC in a population-based setting with representative real-life data.
\end{abstract}

Keywords Head and neck cancer · Tumor staging · Cancer registry · Cervical lymph node metastases · Lymph node classifications · Survival

Orlando Guntinas-Lichius

orlando.guntinas@med.uni-jena.de

1 Department of Otorhinolaryngology, Jena University Hospital, Am Klinikum 1, 07747 Jena, Germany

2 Department of Otorhinolaryngology, Suedharzklinikum Nordhausen, Nordhausen, Germany

3 Department of Otorhinolaryngology, Helios-Klinikum Erfurt, Erfurt, Germany

4 Department of Otorhinolaryngology, SRH Zentralklinikum Suhl, Suhl, Germany

5 Department of Otorhinolaryngology, SRH Wald-Klinikum Gera, Gera, Germany

6 Department of Oromaxillofacial Surgery and Plastic Surgery, Jena University Hospital, Jena, Germany

7 University Tumor Center, Jena University Hospital, Jena, Germany

\section{Introduction}

Head and neck cancer (HNC) is the 7th most common cancer worldwide [1]. 12,920 new cases in men and 4,881 in women were reported for Germany for 2015-2016 [2]. Optimal tumor staging is essential for classification, treatment planning and prognosis. Staging is performed according to the TNM (tumor, node, metastasis) classification and the UICC (Union for International Cancer Control) system [3]. Curative and elective neck dissection (ND) as treatment of cervical lymph node metastases play a central role in the therapy of HNC [4-6]. To make correct prognostic statements and to establish an optimal therapeutic concept, the quality of the histopathological findings of the yielded lymph nodes is extremely important. This $\mathrm{pN}$ classification is highly dependent on the total number of lymph nodes removed (TNOD) and histopathological specimen in particular [7]. Therefore, additional classifications have been investigated in recent years regarding to their prognostic significance. Roberts et al. identified the number of positive lymph nodes (PNOD) as a valid prognostic classification [8]. 
In other studies, lymph node ratio (LNR), which is the ratio between PNOD and TNOD, is shown as a superior and independent prognostic classification $[9,10]$. There is a strong dependence on the TNOD, which may be influenced by the extent of ND on one hand and accuracy of histopathological findings on the other hand [11]. Recent studies investigated the impact of a new lymph node classification scheme on OS of tumor patients: the log odds of positive lymph nodes (LODDS). LODDS is defined as the logarithm of the ratio between PNOD and negative lymph nodes [7, 12]. LODDS is already used as a prognostic factor in breast carcinoma, gastric cancer, pancreatic cancer and colorectal carcinoma $[13,14]$. There are only few hospital-based studies and one multi-institution study so far, which considered the influence of LODDS on OS in HNC patients. In these studies, LODDS has been demonstrated as a prognostic classification superior than others such as pN and LNR [7, 12, 15, 16]. LODDS was able to discriminate patients without positive lymph nodes, few nodes or insufficient nodes retrieved [12].

This study investigates the influence of these extended lymph node classifications on OS for the first time on a population basis. In addition, the influences of patient and tumor parameters as well as aspects of ND on OS were analyzed.

\section{Methods}

\section{Ethical considerations}

The Ethics Committee of the Jena University Hospital approved the study (IRB No. 3204-07/11). The Ethics Committee waived the requirement for informed consent of the patients because the study had a non-interventional retrospective design and all data were analyzed anonymously.

\section{Patients}

This population-based cohort study was established on patients who were diagnosed with a primary HNC in the period from January 2009 to December 2010 and were registered in the five Thuringian cancer registries (Erfurt, Gera,,Jena, Nordhausen, Suhl, and Weimar) covering $>98 \%$ of all new HNC patients [17]. These 2 years were selected to allow adequate follow-up. Thuringia is a federal state in Germany and involves a population of about 2.1 million people. In total, 709 new cases of head and neck cancer were registered, i.e., the exact incidence in 2009-2010 was 31.6 new cases per 100,000 habitants. All patients without surgery treatment which included a ND, patients with skin cancer or who had metastasis of other entities in the head and neck were excluded. 401 patients build the final dataset. In addition to the cancer registry data, cases were divided according to the International
Classification of Disease for Oncology (ICD-O-3) into lip, oral cavity, nasopharynx, oropharynx, hypopharynx, larynx, salivary glands and nose/paranasal sinus [18]. Furthermore, all pathological stages of the primary cancer were recorded using the TNM-classification, 7th edition [3]: tumor size T, regional cervical lymph node status $\mathrm{N}$, distant metastases $M$, resection status $R$, grading $G$, lymph vessel invasion $\mathrm{L}$, venous invasion $\mathrm{V}$, and extracapsular spreading ECS. In a few cases, the primary head and neck tumor was not resected, but a ND was performed. Since no histopathologically confirmed tumor size was available in these cases, the clinical tumor size cT was integrated into the value labeling of the variables and used for these cases. In addition to the cancer registry data, all necessary information on the ND could be obtained from the surgical and histopathological reports from the patients' charts.

\section{Lymph node classification}

Lymph node ratio (LNR) was determined as the quotient from the total number of positive lymph nodes (PNOD) and the total number of lymph nodes removed (TNOD) [15]. The natural logarithm of the quotient of PNOD and the number of negative lymph nodes is called LODDS ( $=\log$ odds of positive lymph nodes) and is calculated as follows: $\log ((\mathrm{PNOD}+0.5) /(\mathrm{TNOD}-\mathrm{PNOD}+0.5))$. The value 0.5 was added to both PNOD (= positive number of lymph nodes) and TNOD (= total number of lymph nodes) to avoid a numerical singularity [15].

\section{Statistical analysis}

Descriptive statistical analyses were performed using SPSS Statistics Version 24 (IBM Deutschland GmbH, 71,139 Ehningen, Germany). Nominal parameters, such as patient characteristics, ND and tumor characteristics were analyzed with absolute and relative frequency calculation. Metric data were evaluated by calculating the median and the range as well as the mean and the standard deviation. The influence of all variables on OS was analyzed using the log-rank test. The Kaplan-Meier method was chosen to graphically represent the significant factors influencing OS. A significance level of $p=0.05$ was chosen. Variables with $p<0.05$ were rated as statistically significant. The time periods to be analyzed were 2-year and 5-year survival rates. Multivariable analyses using Cox proportional hazard ratio (HR) with corresponding 95\% confidence interval (CI) were performed to verify an independent influence of all significant factors influencing OS in the univariate analysis. A significance level of $p=0.05$ was set. 


\section{Results}

\section{Patient's characteristics and tumor characteristics}

In total, 401 patients (321 men; 80\%) were included, i.e., the ND rate in Thuringia for HNC in 2009-2010 was 17.9 per 100,000 habitants. The median age at diagnosis was 57 years (range 23-86 years). As shown in Table 1, the largest proportion of all malignancies was represented by oral cavity carcinoma (40\%). Furthermore, oropharyngeal carcinoma represented a frequent tumor location (21\%). Squamous cell carcinomas accounted for $92 \%$ of the primary tumors (Table 2). One third of the patients had an advanced $\mathrm{T}$ classification (pT3/T4: 35\%). Regarding the resection status of the primary tumors, R0 resection was achieved in $82 \%$ of patients. R1 resection occurred in $8 \%$ and $\mathrm{R} 2$ resection in $2 \%$ of cases. In 19 patients, no surgical therapy of the primary tumor was performed. At the time of diagnosis, almost half of the patient collective (47\%) was already in UICC stage IV. The distribution of the other half of the collective was evenly divided between UICC stages I, II, and III in $16 \%$ each. Selective ND was predominantly performed in unilateral operations ( $81 \%)$. Only 33 out of 176 unilateral operations were modified radical or radical ND (19\%). In the case of bilateral operations, in two third of the cases (66\%) selective ND and in only on third of the cases (34\%) modified radical or radical ND was performed on the side of the tumor.

\section{Cervical lymph node status and classifications}

Overall, regional lymph node metastasis was histologically proven in more than half of all patients $(\mathrm{pN}+; \mathrm{N}=208$; $52 \%$ ). Most of these patients (74\%) had a pN2 lymph node status. In addition, extracapsular spreading (ECS) of lymph node metastases was detected in 66 of 208 cases (32\%). In 90 of 208 cases (43\%), no statement was made regarding ECS. In all unilateral ND, a mean number of $13.6 \pm 10.4$ lymph nodes were yielded. Of these, a mean number of $1.4 \pm 2.7$ lymph nodes were positive (Median 0 , range $=0-16$ ). The mean LNR was $0.16 \pm 0.27$ (Median 0 , range $=0-1)$. The median LODDS was $-0.96 \pm 0.57$ (Median -1.11 , range $=-2$ to 0.66 ). In all ND performed bilaterally, a mean number of $29.5 \pm 16.3$ lymph nodes were yielded. Of these, a mean number of $2.2 \pm 4.1$ lymph nodes were positive (Median 1, range $=0-35$ ). The mean LNR was $0.09 \pm 0.15$ (Median 0.03, range $=0-1$ ). The mean LODDS was $-1.2 \pm 0.57$ (Median -1.24, range $=-2.14$ to 1.04 ).

\section{Overall survival}

Median follow-up was 51 months (range: 0-115) and median follow-up for patients alive was 62 months (range (0-115). The univariable analyses showed (Supplementary Table S1) that higher age was associated with lower survival probability $(p=0.020)$. Tumor parameters $\mathrm{pT}$, $\mathrm{pN}$ and $\mathrm{M}$ showed significant influence on OS. Patients with a T3/T4 tumor had a significantly worse 5 -year OS rate $(5$-year $\mathrm{OS}=55.7 \% ; p<0.001)$ than patients with a T1/T2 tumor (5-year OS $=78.5 \%$ ). Increasing lymph node involvement, the presence of distant metastases and advanced stage of the UICC tumor classification resulted in a lower OS (all $p<0.05)$. Incomplete resection (R1) results in worse outcome $(p<0.0001)$. Existing lymphatic vessel invasion as well as venous invasion also were negative prognostic factors for OS (both $p<0.001$ ). Oropharyngeal carcinoma was the only tumor entity to show significantly better OS than the other localizations $(p=0.040)$. The presence of more than one affected lymph node was associated with a reduction in OS (5-year OS $=59.6 \%)$ compared to $\mathrm{PNOD}=0-1$ (5-year OS $=77.2 \% ; p<0.001$; Fig. 1). A LNR between 0 and $10 \%$ showed a 2 -year OS of $86.5 \%$. A LNR of $>10 \%$ reduced the 2 -year OS by $20.8 \%$ $(p=<0.001)$. The 5 -year OS rate of LODDS $\leq-1.0$ was $79.0 \%$. LODDS $>-1.0$ resulted in a reduced 5 -year OS of $57.2 \%(p<0.001)$.

In a multivariable analysis of all variables influencing OS, (model I, Table 3), the only remaining independent risk factors were age $>57$ years, a pT4 tumor, and incomplete tumor resection (R1). Accordingly, patients older than 57 years had a 2.21-fold increased hazard of death $(p=0.007)$. Patients who had a pT4 tumor, had a 3.38-fold increased hazard of death $(p=0.045)$. The hazard of death was increased by 3.52 for patients with incomplete resections. To focus on the role of the lymph node status, only the UICC stage, the number of positive lymph nodes (PNOD) and the lymph node indices (LNR and LODDS) were included in a second multivariable model (model II, Table 3). A UICC stage II had a 5.381-fold increased hazard of death $(p=0.008)$. At a UICC stage III, 
Table 1 Patients' characteristics

\begin{tabular}{|c|c|c|c|}
\hline \multicolumn{2}{|l|}{ Parameter } & $\begin{array}{l}\text { Frequency } \\
(\mathrm{N})\end{array}$ & $\%$ \\
\hline \multicolumn{4}{|l|}{ Gender } \\
\hline \multicolumn{2}{|l|}{ Male } & 321 & 80 \\
\hline \multicolumn{2}{|l|}{ Female } & 80 & 20 \\
\hline \multicolumn{4}{|l|}{ Localization } \\
\hline \multicolumn{2}{|l|}{ Cavity of the mouth } & 159 & 40 \\
\hline \multicolumn{2}{|l|}{ Oropharynx } & 83 & 21 \\
\hline \multicolumn{2}{|l|}{ Hypopharynx } & 49 & 12 \\
\hline \multicolumn{2}{|l|}{ Larynx } & 55 & 14 \\
\hline \multicolumn{2}{|l|}{ Salivary glands } & 31 & 8 \\
\hline \multicolumn{2}{|l|}{ Lip } & 9 & 2 \\
\hline \multicolumn{2}{|l|}{ Nasopharynx } & 5 & 1 \\
\hline \multicolumn{2}{|c|}{ Nose and paranasal sinus } & 5 & 1 \\
\hline \multicolumn{2}{|l|}{ Middle ear } & 1 & $<1$ \\
\hline \multicolumn{2}{|l|}{ CUP } & 4 & 1 \\
\hline \multicolumn{4}{|l|}{ Neck dissection } \\
\hline \multicolumn{2}{|l|}{ Unilateral } & 176 & 42 \\
\hline \multicolumn{2}{|l|}{ Bilateral } & 247 & 58 \\
\hline \multicolumn{4}{|c|}{$\begin{array}{l}\text { Type of neck dissection (unilateral opera- } \\
\text { tion) }\end{array}$} \\
\hline \multicolumn{2}{|l|}{ Selective } & 143 & 81 \\
\hline \multicolumn{2}{|c|}{ Modified radical or radical } & 33 & 19 \\
\hline \multicolumn{4}{|c|}{$\begin{array}{l}\text { Type of neck dissection (bilateral opera- } \\
\text { tion) }\end{array}$} \\
\hline \multicolumn{2}{|c|}{ Selective (ipsilateral) } & 163 & 66 \\
\hline \multicolumn{2}{|c|}{ Modified radical or radical (ipsilateral) } & 84 & 34 \\
\hline \multicolumn{2}{|c|}{ Selective (contralateral) } & 217 & 88 \\
\hline Modified radical or ra & dical (contralateral) & 30 & 12 \\
\hline Recurrence & & & \\
\hline No & & 115 & 29 \\
\hline Yes & & 286 & 71 \\
\hline Death & & & \\
\hline No & & 295 & 74 \\
\hline Yes & & 106 & 26 \\
\hline Year of diagnosis & & & \\
\hline 2009 & & 211 & 53 \\
\hline 2010 & & 190 & 47 \\
\hline Thuringian tumor reg & istry & & \\
\hline Jena & & 148 & 37 \\
\hline Erfurt & & 134 & 33 \\
\hline Gera & & 44 & 11 \\
\hline Nordhausen & & 30 & 8 \\
\hline Suhl & & 45 & 11 \\
\hline & Mean \pm SD & Median, R & \\
\hline Age (years) & $58.7 \pm 10.4$ & $57,23-86$ & \\
\hline Follow-up (months) & $48 \pm 32.1$ & $51,0-115$ & \\
\hline $\begin{array}{l}\text { Follow-up of patients } \\
\text { alive (months) }\end{array}$ & $58 \pm 30.4$ & $62,0-115$ & \\
\hline
\end{tabular}

${ }^{*} C U P$ carcinoma of unknown primary, $S D$ standard deviation hazard of death increased (HR 4.312; 95\% CI 1.234-15.067, $p=0.022$ ) and at the highest tumor stage, UICC stage IV, there was an 9.218-fold increased hazard of death (HR 9.218; 95\% CI $2.721-31.224 ; p<0.001)$. The number of positive lymph nodes as well as the lymph node ratio showed no independent influence on OS. In contrast, the hazard of death increased for LODDS $>-1.0$ (HR 2.120; 95\% CI 1.129-3.982; $p=0.019$ ).

\section{Discussion}

In this population-based study, different lymph node classifications were analyzed for OS in all new HNC treated in a federal state of Germany. LODDS $>-1.0$ was validated as the only independent significant lymph node predicator for lower OS. PNOD and LNR showed no independent influence on OS. LODDS has been shown in hospital-based data as an independent predictor of OS in other carcinoma types [7, 13, 14, 19, 20]. In addition, recent studies have investigated the impact of LODDS on HNC tumors. Yildiz et al. showed in a retrospective single-institution study of 225 patients that LODDS was an independent prognostic factor. LODDS $>-1.0$ was a predictor for lower OS [15]. In a multi-institution retrospective analysis of 3958 cases of oral cancer based on the Surveillance, Epidemiology and End Results (SEER) database, LODDS was shown to be a more accurate predictor of the 5-year disease specific survival than other lymph node classifications [21]. In this SEER study, all patients with fewer than ten lymph nodes yielded were excluded because this was defined as an inadequate ND. This makes it difficult to make final conclusions about the quality of LODDS especially in the case of few yielded lymph nodes. Safi et al. demonstrated in a retrospective single-institution study of 499 patients with oral cancer that LODDS is a better predictor of regional recurrence than LNR or PNOD [22]. In contrast, Subramaniam et al. showed different results in a retrospective single-institution analysis of 643 patients with oral cancer. The PNOD and LNR were the best predictor for OS and disease free survival [23]. Subramaniam divided LODDS in three risk subcategories. Patient with the lowest subcategory (LODDS $<-1.68$ ) were not included. In their analysis, patients with higher risk subcategories were overrepresented and the cut-off-values for the different risk subcategories for LODDS was subject. Additionally, they suggested that $\mathrm{pN}$ and LNR were better in terms of model discrimination [23]. Jin et al. demonstrated in a retrospective single-institution study again only focused on 233 patients with oral cancer that LODDS has the stronger predictive power compared to LNR and PNOD. LODDS was the best lymph node predictor for 10-year disease-specific survival. The cutoff value for a lower disease-specific 
Table 2 Histopathology and lymph node characteristics

\begin{tabular}{|c|c|c|}
\hline Parameter & Frequency $(\mathrm{N})$ & $\%$ \\
\hline \multicolumn{3}{|l|}{ pT classification } \\
\hline T0/Tis & 6 & 1 \\
\hline $\mathrm{T} 1$ & 102 & 25 \\
\hline $\mathrm{T} 2$ & 126 & 31 \\
\hline $\mathrm{T} 3$ & 74 & 18 \\
\hline $\mathrm{T} 4$ & 65 & 16 \\
\hline $\mathrm{Tx}$ & 28 & 7 \\
\hline \multicolumn{3}{|l|}{ pN classification } \\
\hline N0 & 189 & 47 \\
\hline N1 & 50 & 13 \\
\hline $\mathrm{N} 2$ & 154 & 38 \\
\hline N3 & 4 & 1 \\
\hline $\mathrm{Nx}$ & 4 & 1 \\
\hline \multicolumn{3}{|l|}{ M classification } \\
\hline M0 & 378 & 94 \\
\hline M1 & 9 & 2 \\
\hline $\mathrm{Mx}$ & 14 & 3 \\
\hline \multicolumn{3}{|c|}{$\begin{array}{l}\text { Stage (AJCC 7th edi- } \\
\text { tion 2010) }\end{array}$} \\
\hline I & 5 & 1 \\
\hline II & 63 & 16 \\
\hline III & 66 & 16 \\
\hline IV & 189 & 47 \\
\hline Unstaged & 14 & 3 \\
\hline \multicolumn{3}{|l|}{ Tumor margins } \\
\hline R0 & 327 & 82 \\
\hline $\mathrm{R}+$ & 42 & 10 \\
\hline $\mathrm{Rx}$ & 8 & 8 \\
\hline $\begin{array}{l}\text { No primary tumor } \\
\text { excision }\end{array}$ & 19 & 5 \\
\hline Missing & 5 & 1 \\
\hline \multicolumn{3}{|c|}{ Tumor differentiation } \\
\hline $\mathrm{G} 1 / 2$ & 260 & 65 \\
\hline G3 & 111 & 28 \\
\hline Unknown & 30 & 7 \\
\hline \multicolumn{3}{|l|}{$\begin{array}{l}\text { Lymphovascular } \\
\text { invasion }\end{array}$} \\
\hline L0 & 186 & 46 \\
\hline L1 & 77 & 19 \\
\hline Unknown & 138 & 34 \\
\hline \multicolumn{3}{|l|}{ Venous invasion } \\
\hline V0 & 238 & 59 \\
\hline V1 & 11 & 3 \\
\hline Unknown & 152 & 38 \\
\hline \multicolumn{3}{|c|}{ Extracapsular spread } \\
\hline ECS- & 66 & 16 \\
\hline $\mathrm{ECS}+$ & 55 & 14 \\
\hline Unknown & 90 & 22 \\
\hline $\mathrm{N} 0 / \mathrm{Nx}$ & 190 & 47 \\
\hline
\end{tabular}

Table 2 (continued)

\begin{tabular}{|c|c|c|}
\hline Parameter & Frequency (N) & $\%$ \\
\hline \multicolumn{3}{|l|}{ Histology } \\
\hline $\begin{array}{l}\text { Squamous cell car- } \\
\text { cinoma }\end{array}$ & 368 & 92 \\
\hline Adenocarcinoma & 7 & 2 \\
\hline \multirow[t]{2}{*}{ Other carcinoma } & 26 & 6 \\
\hline & Mean \pm SD & Median, Range \\
\hline \multicolumn{3}{|l|}{$\begin{array}{l}\text { Type of neck dis- } \\
\text { section (unilateral } \\
\text { operation) }\end{array}$} \\
\hline $\begin{array}{l}\text { Lymph nodes } \\
\text { resected (TNOD) }\end{array}$ & $13.6 \pm 10.4$ & $11,0-63$ \\
\hline $\begin{array}{l}\text { Positive lymph nodes } \\
\text { (PNOD) }\end{array}$ & $1.4 \pm 2.7$ & $0,0-16$ \\
\hline $\begin{array}{l}\text { Lymph node ratio } \\
\text { (LNR) }\end{array}$ & $0.16 \pm 0.27$ & $0,0-1$ \\
\hline $\begin{array}{l}\text { Log odds of posi- } \\
\text { tive lymph nodes } \\
\text { (LODDS) }\end{array}$ & $-0.96 \pm 0.57$ & $-1.11,-2$ to 0.66 \\
\hline \multicolumn{3}{|l|}{$\begin{array}{l}\text { Type of neck dis- } \\
\text { section (bilateral } \\
\text { operation) }\end{array}$} \\
\hline $\begin{array}{l}\text { Lymph nodes } \\
\text { resected (TNOD) }\end{array}$ & $29.5 \pm 16.3$ & $27,0-84$ \\
\hline $\begin{array}{l}\text { Positive lymph nodes } \\
\text { (PNOD) }\end{array}$ & $2.2 \pm 4.1$ & $1,0-35$ \\
\hline $\begin{array}{l}\text { Lymph node ratio } \\
\text { (LNR) }\end{array}$ & $0.09 \pm 0.15$ & $0.03,0-1$ \\
\hline $\begin{array}{l}\text { Log odds of posi- } \\
\text { tive lymph nodes } \\
\text { (LODDS) }\end{array}$ & $-1.2 \pm 0.57$ & $-1.24,-2.14$ to 1.04 \\
\hline
\end{tabular}

*AJCC American joint committee on cancer, TNOD total number of lymph node, $P N O D$ number of positive lymph node, $L N R$ lymph node ratio, $L O D D S$ log odds of positive lymph node, ECS extracapsular spread, $S D$ standard deviation

survival was LODDS $>-1.491$. LODDS can differentiate better than LNR and PNOD, especially when TNOD $<18$ or few positive lymph nodes were yielded in inadequately performed ND. In addition, by adding 0.5 to the denominator and numerator, LODDS can differentiate OS of patients without positive lymph nodes [16]. In contrast, Bao et al. do not indicate a predictive advantage of LODDS over PODS with respect to 5-year OS in a prospective study of 706 patients with oral cancer. Furthermore, they showed a nonlinear relationship between $\mathrm{OS}$ and the number of negative lymph nodes. OS was reduced and performance of LODDS as lymph node predictor was decreased when more than 40 negative lymph nodes were yielded. It was speculated that the lower OS with increasing lymph node yield was caused by increased postoperative complications caused 

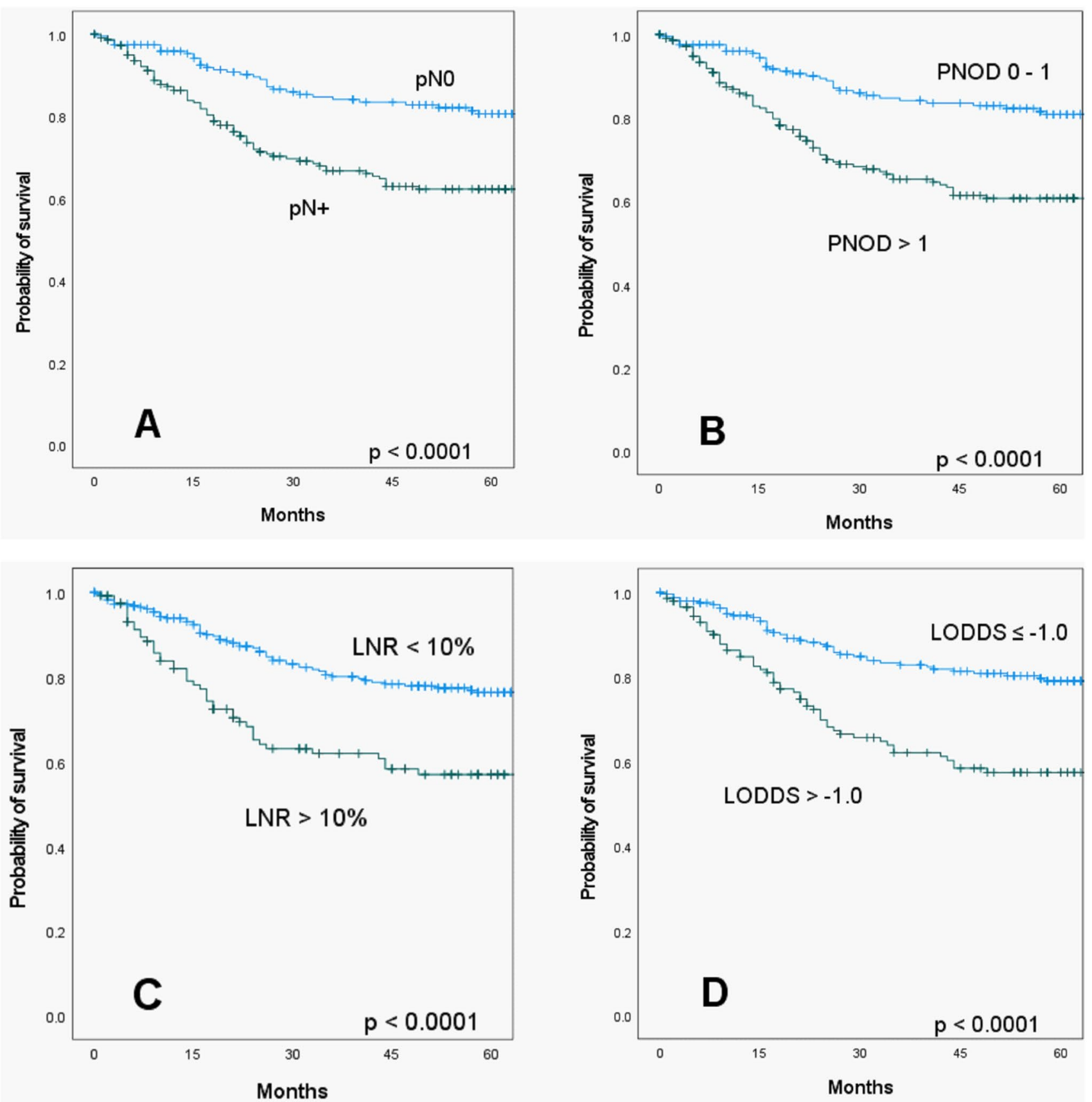

Fig. 1 Kaplan-Meier curves of overall survival according to pN status (A), number of positive lymph nodes (PNOD) (B), lymph node ratio (LNR) (C), and log odds of positive lymph nodes (LODDS) (D)

by the more extensive lymphadenectomy[24]. This kind of nonlinear relation between OS and the number of negative lymph nodes was already reported by Ebrahimi et al. [25]. The study of Bao et al. has some limitations. First of all, it is a single-institution study. Bao et al. divided also LODDS in three subcategories and the cut-off-values for the different subcategories was subject. They did not evaluate other lymph node classification rather than other prognostic values such as the type of ND.

According to the present analysis that included all types of HNC, LODDS may give a better and more accurate indication of OS, especially in patients without positive lymph nodes. The present study is the first populationbased analysis of its kind and can accordingly give a very good patient representative of a real-world clinical 
Table 3 Multivariable analysis of risk factors for head and neck cancer overall survival

\begin{tabular}{|c|c|c|c|c|c|}
\hline \multicolumn{2}{|l|}{ Factor } & \multirow[t]{2}{*}{$\mathrm{HR} *$} & \multirow[t]{2}{*}{ Lower 95\%CI } & \multirow[t]{2}{*}{ Upper $95 \%$ CI } & \multirow[t]{2}{*}{$p^{*}$} \\
\hline \multicolumn{2}{|l|}{ Model I } & & & & \\
\hline \multirow[t]{2}{*}{ Age } & $\leq 57$ years & 1 & Reference & & \\
\hline & $>57$ years & 2.21 & 1.240 & 3.938 & 0.007 \\
\hline \multirow[t]{2}{*}{ Gender } & Female & 1 & Reference & & \\
\hline & Male & & & & \\
\hline \multirow[t]{4}{*}{ pT } & $\mathrm{T} 1$ & 1 & Reference & & \\
\hline & $\mathrm{T} 2$ & 1.242 & 0.397 & 3.887 & 0.710 \\
\hline & $\mathrm{T} 3$ & 1.858 & 0.595 & 5.796 & 0.286 \\
\hline & $\mathrm{T} 4$ & 3.378 & 1.027 & 11.112 & 0.045 \\
\hline \multirow[t]{4}{*}{$\mathrm{pN}$} & N0 & 1 & Reference & & \\
\hline & N1 & 1.005 & 0.341 & 2.962 & 0.992 \\
\hline & $\mathrm{N} 2$ & 1.341 & 0.347 & 5.184 & 0.671 \\
\hline & N3 & & & & \\
\hline \multirow[t]{2}{*}{ M } & M0 & 1 & & & \\
\hline & M1 & 1.995 & 0.396 & 10.048 & 0.402 \\
\hline \multirow[t]{2}{*}{$\mathrm{R}$} & R0 & 1 & & & \\
\hline & $\mathrm{R} 1$ & 3.523 & 1.492 & 8.317 & 0.004 \\
\hline \multirow[t]{4}{*}{ Stage } & I & 1 & Reference & & \\
\hline & II & 4.004 & 0.599 & 26.772 & 0.152 \\
\hline & III & 3.220 & 0.481 & 21.547 & 0.228 \\
\hline & IV & 3.700 & 0.503 & 27.200 & 0.199 \\
\hline \multirow[t]{2}{*}{$\mathrm{L}$} & L0 & 1 & Reference & & \\
\hline & L1 & 1.039 & 0.533 & 2.027 & 0.910 \\
\hline \multirow[t]{2}{*}{ V } & V0 & 1 & Reference & & \\
\hline & $\mathrm{V} 1$ & 1.779 & 0.684 & 4.625 & 0.237 \\
\hline \multirow[t]{2}{*}{ Tumor localization } & Other localization & 1 & Reference & & \\
\hline & Oropharynx & 0.460 & 0.194 & 1.093 & 0.079 \\
\hline \multirow[t]{2}{*}{ Ipsilateral neck dissection } & Modified radical/radical & 1 & Reference & & \\
\hline & Selective & 0.953 & 0.531 & 1.712 & 0.873 \\
\hline \multirow[t]{2}{*}{ PNOD } & $0-1$ & 1 & Reference & & \\
\hline & $>1$ & 1.112 & 0.368 & 3.353 & 0.851 \\
\hline \multirow[t]{2}{*}{ LNR } & $0-10 \%$ & 1 & Reference & & \\
\hline & $>10 \%$ & 0.606 & 0.230 & 1.602 & 0.313 \\
\hline \multirow[t]{2}{*}{ LODDS } & $\leq-1,0$ & 1 & Reference & & \\
\hline & $>-1,0$ & 2.166 & 0.860 & 5.456 & 0.101 \\
\hline \multicolumn{6}{|l|}{ Model II } \\
\hline \multirow[t]{4}{*}{ Stage } & I & 1 & Reference & & \\
\hline & II & 5.381 & 1.557 & 18.589 & 0.008 \\
\hline & III & 4.312 & 1.234 & 15.067 & 0.022 \\
\hline & IV & 9.218 & 2.721 & 31.224 & $<0.001$ \\
\hline \multirow[t]{2}{*}{ PNOD } & $0-1$ & 1 & Reference & & \\
\hline & $>1$ & 0.677 & 0.362 & 1.266 & 0.222 \\
\hline LNR & $0-10 \%$ & 1 & Reference & & \\
\hline & $>10 \%$ & 0.808 & 0.420 & 1.552 & 0.522 \\
\hline LODDS & $\leq-1,0$ & 1 & Reference & & \\
\hline & $>-1,0$ & 2.120 & 1.129 & 3.982 & 0.019 \\
\hline
\end{tabular}

*Statistically significant difference compared to reference $(p<0.05), H R$ hazard ratio, $C I$ confidence interval, $T N O D$ total number of lymph nodes, $P N O D$ number of positive lymph node, $L N R$ lymph node ratio, $L O D D S \log$ odds of positive lymph nodes 
routine setting. The sample size was relatively large and so differences of head and neck subsites could be analyzed. However, this study has some limitations that need to be addressed. The retrospective analysis cannot guarantee a standardized treatment decision of the different head and neck surgeons during ND. It is well known that surgical standardization increases the quality and number of yielded lymph nodes in a ND [11]. The number of yielded lymph nodes and the decision to perform unilateral or bilateral ND were also not standardized. The average number of lymph nodes removed in unilateral ND in this study was 13.6 lymph nodes. However, a sampling of 18 lymph nodes is recommended. The quality of ND increases with the number of at least 18 lymph nodes $[25,26]$. In addition, there is no standardization in the reporting of lymph nodes by pathologists.

\section{Conclusion}

This study provides a first population-based analysis and can give a much better assessment of lymph node parameters than a single-institution study. LODDS seems to be a promising predictor. Confirmation of the results with a larger patient population in a prospective trial and at best also in other countries is needed. The LODDS cutoff values were set by several authors subjectively and have to be standardized and validated. In conclusion, the results of this study demonstrate superiority of the lymph node classification LODDS as a survival predictor for HNC over the commonly used classification LNR and PNOD. However, further research is needed to evaluate the reliability of LODDS in the differentiation in numbers of yielded lymph nodes.

Supplementary Information The online version contains supplementary material available at https://doi.org/10.1007/s00405-021-07176-8.

Acknowledgements We like to thank all departments and outpatient clinics that were involved in the treatment and data collection of the patients. We thank the coordinators of the five Thuringian cancer registries for the collaboration: Hubert Göbel (Erfurt), Uwe Funke (Gera), Ulrike Burger (Jena), Manuela Geist (Nordhausen) and Matthias Wackes (Suhl).

Funding Open Access funding enabled and organized by Projekt DEAL.

\section{Declarations}

Conflicts of interest The authors have no conflicts of interest.

Ethical approval All procedures performed in studies involving human participants were in accordance with the ethical standards of the institutional and/or national research committee and with the 1964 Helsinki declaration and its later amendments or comparable ethical standards.
The Ethics Committee waived the requirement for informed consent of the patients because the study had a non-interventional retrospective design and all data were analyzed anonymously.

Open Access This article is licensed under a Creative Commons Attribution 4.0 International License, which permits use, sharing, adaptation, distribution and reproduction in any medium or format, as long as you give appropriate credit to the original author(s) and the source, provide a link to the Creative Commons licence, and indicate if changes were made. The images or other third party material in this article are included in the article's Creative Commons licence, unless indicated otherwise in a credit line to the material. If material is not included in the article's Creative Commons licence and your intended use is not permitted by statutory regulation or exceeds the permitted use, you will need to obtain permission directly from the copyright holder. To view a copy of this licence, visit http://creativecommons.org/licenses/by/4.0/.

\section{References}

1. Bray F, Ferlay J, Soerjomataram I, Siegel RL, Torre LA, Jemal A (2018) Global cancer statistics 2018: GLOBOCAN estimates of incidence and mortality worldwide for 36 cancers in 185 countries. CA Cancer J Clin 68:394-424

2. Krebsregisterdaten Zf, Robert-Koch-Institut. Datenbankabfrage mit Schätzung der Inzidenz, Prävalenz und des Überlebens von Krebs in Deutschland auf Basis der epidemiologischen Landeskrebsregisterdaten. 2021: https://www.krebsdaten.de/ Krebs/DE/Content/Publikationen/Krebs_in_Deutschland/krebs_ in_deutschland_inhalt.html (last access: 04-July-2021)

3. Sobin LH, Gospodarowicz MK, Wittekind C (2010) TNM classification of malignant tumours/edited by Sobin LH, Gospodarowicz MK, and Wittekind CH. 7th ed. 2009. ed. England: Chichester, West Sussex, UK ; Hoboken, NJ : Wiley-Blackwell

4. D'Cruz AK, Vaish R, Kapre N, Dandekar M, Gupta S, Hawaldar $R$ et al (2015) Elective versus therapeutic neck dissection in nodenegative oral cancer. N Engl J Med 373:521-529

5. Coatesworth AP, MacLennan K (2002) Squamous cell carcinoma of the upper aerodigestive tract: the prevalence of microscopic extracapsular spread and soft tissue deposits in the clinically N0 neck. Head Neck 24:258-261

6. Robbins KT, Shaha AR, Medina JE, Califano JA, Wolf GT, Ferlito A et al (2008) Consensus statement on the classification and terminology of neck dissection. Arch Otolaryngol Head Neck Surg 134:536-538

7. Sun Z, Xu Y, de Li M, Wang ZN, Zhu GL, Huang BJ et al (2010) Log odds of positive lymph nodes: a novel prognostic indicator superior to the number-based and the ratio-based $\mathrm{N}$ category for gastric cancer patients with R0 resection. Cancer 116:2571-2580

8. Roberts TJ, Colevas AD, Hara W, Holsinger FC, Oakley-Girvan I, Divi V (2016) Number of positive nodes is superior to the lymph node ratio and American Joint Committee on Cancer N staging for the prognosis of surgically treated head and neck squamous cell carcinomas. Cancer 122:1388-1397

9. Süslü N, Hoşal AS, Sözeri B (2010) Prognostic value of metastatic lymph node ratio in node-positive head and neck carcinomas. Am J Otolaryngol 31:315-319

10. Ebrahimi A, Clark JR, Zhang WJ, Elliott MS, Gao K, Milross CG et al (2011) Lymph node ratio as an independent prognostic factor in oral squamous cell carcinoma. Head Neck 33:1245-1251

11. Marres CC, de Ridder M, Hegger I, van Velthuysen ML, Hauptmann M, Navran A et al (2014) The influence of nodal yield in 
neck dissections on lymph node ratio in head and neck cancer. Oral Oncol 50:59-64

12. Lee CC, Lin YS, Kang BH, Chang KP, Chi CC, Lin MY et al (2017) Incorporation of log odds of positive lymph nodes into the AJCC TNM classification improves prediction of survival in oral cancer. Clin Otolaryngol 42:425-432

13. Qiu MZ, Qiu HJ, Wang ZQ, Ren C, Wang DS, Zhang DS et al (2012) The tumor-log odds of positive lymph nodes-metastasis staging system, a promising new staging system for gastric cancer after D2 resection in China. PLoS ONE 7:e31736

14. Arslan NC, Sokmen S, Canda AE, Terzi C, Sarioglu S (2014) The prognostic impact of the log odds of positive lymph nodes in colon cancer. Colorectal Dis 16:O386-O392

15. Yildiz MM, Petersen I, Eigendorff E, Schlattmann P, GuntinasLichius O (2016) Which is the most suitable lymph node predictor for overall survival after primary surgery of head and neck cancer: $\mathrm{pN}$, the number or the ratio of positive lymph nodes, or log odds? J Cancer Res Clin Oncol 142:885-893

16. Jin W, Zhu Z, Wu Y, Ding X, Wu H, Song X et al (2020) Prognostic value of log odds of positive lymph nodes in patients with resectable oral squamous cell carcinoma. Oral Oncol 108:104709

17. Dittberner A, Friedl B, Wittig A, Buentzel J, Kaftan H, Boeger D, et al (2020) Gender Disparities in Epidemiology, Treatment, and Outcome for Head and Neck Cancer in Germany: A PopulationBased Long-Term Analysis from 1996 to 2016 of the Thuringian Cancer Registry. Cancers (Basel). 12

18. Fritz A, Percy C, Jack A, Shanmugaratnam K, Sobin L, Parkin DM et al (2013) International classification of diseases for oncology (ICD-O) - 3rd edition, 1st revision. World Health Organization, Malta

19. Chen LJ, Chung KP, Chang YJ, Chang YJ (2015) Ratio and log odds of positive lymph nodes in breast cancer patients with mastectomy. Surg Oncol 24:239-247
20. Gu P, Deng J, Sun Z, Wang Z, Wang W, Liang H et al (2021) Superiority of log odds of positive lymph nodes (LODDS) for prognostic prediction after gastric cancer surgery: a multi-institutional analysis of 7620 patients in China. Surg Today 51:101-110

21. Lee CC, Su YC, Hung SK, Chen PC, Huang CI, Huang WL et al (2017) Recommendation for incorporation of a different lymph node scoring system in future AJCC N category for oral cancer. Sci Rep 7:14117

22. Safi AF, Kauke M, Grandoch A, Nickenig HJ, Drebber U, Zöller $\mathrm{J}$ et al (2017) The importance of log odds of positive lymph nodes for locoregional recurrence in oral squamous cell carcinoma. Oral Oncol 72:48-55

23. Subramaniam N, Balasubramanian D, Kumar N, Murthy S, Vijayan SN, Nambiar A et al (2019) Lymph node staging systems in oral squamous cell carcinoma: A comparative analysis. Oral Oncol 97:92-98

24. Bao X, Chen F, Qiu Y, Shi B, Lin L, He B (2020) Log odds of positive lymph nodes is not superior to the number of positive lymph nodes in predicting overall survival in patients with oral squamous cell carcinomas. J Oral Maxillofac Surg 78:305-312

25. Ebrahimi A, Zhang WJ, Gao K, Clark JR (2011) Nodal yield and survival in oral squamous cancer: Defining the standard of care. Cancer 117:2917-2925

26. Divi V, Harris J, Harari PM, Cooper JS, McHugh J, Bell D et al (2016) Establishing quality indicators for neck dissection: Correlating the number of lymph nodes with oncologic outcomes (NRG Oncology RTOG 9501 and RTOG 0234). Cancer 122:3464-3471

Publisher's Note Springer Nature remains neutral with regard to jurisdictional claims in published maps and institutional affiliations. 